\title{
Atividade pozolânica da sílica ativa: análise em pastas cimentícias com diferentes teores de substituição
}

\author{
Pozzolanic activity of silica fume: analysis \\ in cement pastes with different substitution levels
}

Marcella Amaral ${ }^{1}$, Gustavo Macioski ${ }^{1}$, Marcelo Henrique Farias de Medeiros ${ }^{1}$

\begin{abstract}
${ }^{1}$ Programa de Pós-Graduação em Engenharia de Construção Civil da Universidade Federal do Paraná, Centro Politécnico, Jardim das Américas, Bloco III, Caixa Postal 19.011, CEP: 81531-980, Curitiba, PR, Brasil. e-mail: marcellamarp@gmail.com; gmacioski@gmail.com; e-mail: medeiros.ufpr@gmail.com
\end{abstract}

\begin{abstract}
RESUMO
A utilização de adições pozolânicas de elevada reatividade, como a sílica ativa, vem sendo amplamente estudada com o intuito de consolidar a sua eficiência em relação ao comportamento mecânico e a durabilidade da matriz cimentícia de concretos e argamassas. O presente estudo tem como objetivo investigar o efeito químico da sílica ativa através da quantificação da reatividade efetiva da sílica ativa incorporada em pastas cimentícias com relação água/aglomerante de 0,58 , considerando a substituição parcial de 5, 10, 15 e $20 \%$ da quantidade total de cimento. Ao longo de 105 dias de hidratação, o teor de portlandita remanescente foi quantificado através de perda gravimétrica simplificada realizada em um forno mufla. Após o período de análise, foi possível identificar que o ensaio Chapelle modificado, indicado pela NBR 15895 (2010), não representa de forma efetiva a atuação pozolânica da sílica ativa nos compósitos cimentícios, visto que houve a permanência de aglomerações do material anidro na matriz cimentícia. Adicionalmente, existe uma menor mobilidade iônica na matriz cimentícia porosa com água nos poros, quando comparada com uma solução aquosa, sendo necessário um estudo da composição do aglomerante em estado endurecido para a quantificação da atividade pozolânica efetiva da sílica ativa utilizada como material suplementar cimentício.
\end{abstract}

Palavras-chave: Materiais suplementares cimentícios. Sílica Ativa. Ensaio Chapelle modificado. Atividade pozolânica. Portlandita.

\begin{abstract}
The use of supplementary cementitious materials with a pozzolanic character, such as silica fume, has been widely studied in order to consolidate its mechanical efficiency and increase in the durability of concretes and mortars. The present paper aims to investigate the chemical effect of silica fume by quantifying the effective reactivity of silica fume incorporated in cementitious pastes with a water/binder ratio of 0.58 , considering the partial replacement of cement in 5, 10, 15 e 20\%. Over 105 days of hydration, the remaining portlandite content was quantified through a simplified gravimetric loss, which was performed in a muffle furnace. After the analysis period, it was possible to identify that the modified Chapelle test, indicated by NBR 15895 (2010), does not effectively represent the pozzolanic activity of silica fume in cementitious composites, since there were many agglomerations of anhydrous material. Moreover, there is less ion mobility in the hardened porous composite than in an aqueous solution, requiring a study of the composition of the hardened binder to quantify the effective pozzolanic activity if the silica fume used as supplementary cementitious material.
\end{abstract}

Keywords: Supplementary Cementitious Materials. Silica Fume. Chapelle modified test. Pozzolanic activity. Portlandite. 


\section{INTRODUÇÃO}

Os materiais cimentícios suplementares são materiais que veem sendo amplamente utilizados nas últimas décadas como substituição parcial do cimento, em concretos e argamassas, devido a promoção da sustentabilidade [1] e a observação de diversos autores quanto a melhoria na performance mecânica e na durabilidade de tais compósitos [2-6].

A sílica ativa (SA) é um subproduto da indústria de silício metálico, com elevado teor de dióxido de silício amorfo $\left(\mathrm{SiO}_{2}\right)$. Tal material, quando utilizado em substituição parcial ao cimento nos compósitos cimentícios, promove um aumento na sua resistência mecânica [7-12] tendo a substituição parcial do cimento por sílica ativa nos teores de $5,10,15$ e $20 \%$ sido responsável pelo aumento de até $36 \%$ na resistência à compressão de concretos com relação água/aglomerante igual a 0,45 após 28 dias de cura [13] e até $11 \%$ em concretos com relação água/aglomerante de 0,60 , após 90 dias de cura [14]. A utilização de sílica ativa promove ainda um aumento na durabilidade de concretos e argamassas em relação à exposição aos íons cloretos e a resistência a corrosão do aço inserido no concreto armado [6, 15-20]. Em contrapartida, MEDEIROS et al. [5] indicam um aumento na velocidade de carbonatação em concretos com a aplicação de $10 \%$ de sílica ativa em substituição ao cimento.

As melhorias promovidas pela incorporação da sílica ativa na matriz cimentícia são atribuídas à capacidade de: (a) melhorar o empacotamento dos sólidos e o refinamento da estrutura porosa, através do preenchimento dos vazios entre os grãos de cimento; (b) prover sítios de nucleação para a precipitação dos produtos de hidratação nas primeiras idades, que contribuem para a formação de cirstais menores de hidróxido de cálcio e com menor tendência de cristalização em orientações preferenciais; (c) exibir propriedades pozolânicas, que consistem na interação com o hidróxido de cálcio proveniente da hidratação do cimento, resultando na formação de silicatos de cálcio hidratado secundários (C-S-H) e na densificação da matriz cimentícia; e (d) aumentar a resistência da zona de transição entre os agregados e a pasta cimentícia por meio da redução da porosidade local e do aumento na qualidade dos produtos de hidratação do cimento nessa região [21-23].

KRAMAR e DUCMAN [24] afirmam que a reatividade da sílica ativa é caracterizada por dois parâmetros. O primeiro consiste na quantidade máxima de cal quimicamente fixada pela adição pozolânica, sendo esta quantidade influenciada pela qualidade, natureza e quantidade de fases ativas presente no material. $\mathrm{O}$ segundo parâmetro é a taxa de reatividade do material, sendo este influenciado pelo tamanhos das partículas, área específica superficial, relação água/sólidos e temperatura de cura [25, 26]. Considerando a elevada finura e a presença de forças coesivas interparticulares (forças de Van der Waals), a sílica ativa possui uma forte tendência de formar aglomerados com elevada resistência à disperção. CARNEIRO et al. [25] e RÊGO et al. [27] observaram, por microscopia eletrônica de varredura (MEV), a aglomeração da sílica ativa formada por partículas menores do material.

A presença de aglomerações pode comprometer a reatividade do material e, consequentemente, as melhorias propriciadas pela sua incorporação. SANJUÁN et al. [7] observaram um aumento nas propriedades físicas e químicas em pastas cimentícias produzidas com partículas de sílica ativa apresentando um diâmetro médio de $10 \mu \mathrm{m}$ quando comparadas com partículas de sílica ativa apresentando um diâmetro médio de 250 $\mu \mathrm{m}$, conduzindo a uma melhoria nas macro propriedades de concretos e argamassas. Adicionalmente, WANG et al. [28] ao analisar pastas cimentícias contendo sílica ativa tratada com sonificação em solução aquosa, verificaram um aumento na atividade pozolânica para a formação de produtos secundários, sendo tal comportamento atribuído à melhor distribuição granulométrica e, consequentemente, a melhor dispersão das partículas nos materiais cimentícios.

Diversos são os métodos utilizados para avaliar a atividade pozolânica das adições minerais reativas [24, 29-31], podendo tal avaliação ser pautada em parâmetros como: (a) consumo de portlandita; (b) grau de reação do material; (c) quantidade de água quimicamente combinada; (d) calor liberado durante a reação; e (e) retração química [32].

O ensaio Chapelle modificado é um método direto e normatizado no Brasil [33] que tem como objetivo determinar o potencial de reação do material, através da quantificação de $\mathrm{Ca}(\mathrm{OH})_{2}$ e sua subsequente redução devido a ocorrência das reações pozolânicas, utilizando o método clássico da titulação química de uma solução aquosa contendo uma quantidade conhecida de adição mineral e de óxido de cálcio $(\mathrm{CaO})$, após um banho-maria $\left(90 \pm 5^{\circ} \mathrm{C}\right)$ com agitação constante durante 16 horas. Segundo QUARCIONI et al. [34] a determinação direta do grau de interação pozolona-óxido de cálcio ou hidróxido de cálcio constitui a melhor maneira para explicar a composição do cimento hidratado e da microestrutura resultante da interação das adições pozolânicas, como a sílica ativa, com o hidróxido de cálcio da matriz cimentícia. HOPPE FILHO et 
al. [35] afirmam ainda que a elevada temperatura do ensaio, maximiza a interação da cal com a adição mineral e garante a solubilização da matriz amorfa da pozolana, promovendo a adequada caracterização da sua reatividade.

Porém, o ensaio pode não representar a reatividade efetiva do material presente nos compósitos cimentícios endurecidos, visto que há uma menor mobilidade iônica e uma maior dificuldade da dissolução dos aglomerados neste caso, quando comparados com a dissolução dos íons no meio aquoso utilizado pelo método. HOPPE FILHO et al. [36], ao investigar a atividade pozolânica de diversas adições reativas em pastas cimentícias com relação água/aglomerante igual a 0,70, através da termogravimetria (TG/DTG) e difração de raios-x, verificaram que os teores de cal fixados por atividade pozolânica determinados pelo ensaio Chapelle modificado são superiores aos obtidos nas pastas das argamassas, sendo tal comportamento atribuído às condições de ensaio.

Nessa perspectiva, o presente estudo tem como objetivo avaliar o efeito químico efetivo da sílica ativa na matriz cimentícia de pastas endurecidas empregando diferentes técnicas, o método Chapelle modificado, indicado pela normatização brasileira (NBR), uma técnica baseada na perda gravimétrica, e, por fim, uma análise qualitativa a partir da difração de raios-x (DRX) e da análise de imagens de microscopia eletrônica de varredura com espectroscopia de energia dispersiva (MEV-EDS). Para tal, foi realizada uma quantificação da reatividade do material ao longo de 105 dias de hidratação, utilizando pastas cimentícias com relação água/aglomerante de 0,58 e considerando a substituição parcial de 5, 10, 15 e 20\% da quantidade total de cimento dos sistemas pos sílica ativa.

\section{MATERIAIS E MÉTODOS}

\subsection{Materiais}

O cimento CPV - ARI foi utilizado para a produção das pastas cimentícias por ser o único cimento do mercado brasileiro com baixo teor de adição mineral, permitindo a melhor análise da influência da substituição do cimento pela sílica ativa. As Tabelas 1 e 2 apresentam, respectivamente, as características físicas do cimento e a composição química dos materiais utilizados neste experimento.

Tabela 1: Caracterização física do cimento Portland.

\begin{tabular}{c|c|c|c|c|c|c|c|c|c}
\hline \multicolumn{2}{c|}{ Finura } & \multicolumn{2}{c|}{ Tempo de pega } & \multicolumn{3}{c|}{$\begin{array}{c}\text { Resistência à compressão } \\
(\mathbf{M P a})\end{array}$} & \multicolumn{3}{c}{ Exigências Químicas (\%) } \\
\hline $\begin{array}{c}\text { Blaine } \\
\left(\mathrm{cm}^{2} / \mathrm{g}\right)\end{array}$ & $\begin{array}{c}\# 200 \\
(\%)\end{array}$ & $\begin{array}{c}\text { Início } \\
(\mathrm{min})\end{array}$ & $\begin{array}{c}\text { Fim } \\
(\mathrm{min})\end{array}$ & 1 dia & 3 dias & 7 dias & 28 dias & $\begin{array}{c}\text { Resíduo Inso- } \\
\text { lúvel }\end{array}$ & $\begin{array}{c}\text { Perda ao } \\
\text { fogo }\end{array}$ \\
\hline 4710 & 0,3 & 250 & 310 & 22,2 & 37,1 & 41,5 & 49,2 & 0,40 & 3,20 \\
\hline
\end{tabular}

Tabela 2: Fluorescência de raios-x do cimento portland e da sílica ativa (SA).

\begin{tabular}{c|c|c|c|c|c|c|c|c|c}
\hline \multirow{2}{*}{ Amostra } & \multicolumn{10}{c}{ Composição Química (\%) } \\
\cline { 2 - 11 } & $\mathbf{C a O}$ & $\mathbf{S i O}_{\mathbf{2}}$ & $\mathbf{A l}_{\mathbf{2}} \mathbf{O}_{\mathbf{3}}$ & $\mathbf{S O}_{\mathbf{3}}$ & $\mathbf{F e}_{\mathbf{2}} \mathbf{O}_{\mathbf{3}}$ & $\mathbf{M g O}$ & $\mathbf{K}_{\mathbf{2}} \mathbf{O}$ & $\mathrm{TiO}_{\mathbf{2}}$ & $\mathbf{N a}_{\mathbf{2}} \mathbf{O}_{\mathbf{5}}$ \\
\hline Cimento & 62,75 & 19,2 & 4,19 & 3,04 & 2,85 & 2,54 & 1,68 & 0,17 & 0,05 \\
\hline SA & 0,51 & 92,49 & 1,91 & 2,08 & 0,13 & - & 2,76 & - & - \\
\hline
\end{tabular}

A distribuição granulométrica dos materiais foi determinada com o auxílio de um granulomêtro a laser, com dispersão prévia por ultrassom durante 60 segundos, sendo realizado pelo Departamento de Engenharia de Materiais do CEFET/MG (Figura 1). 


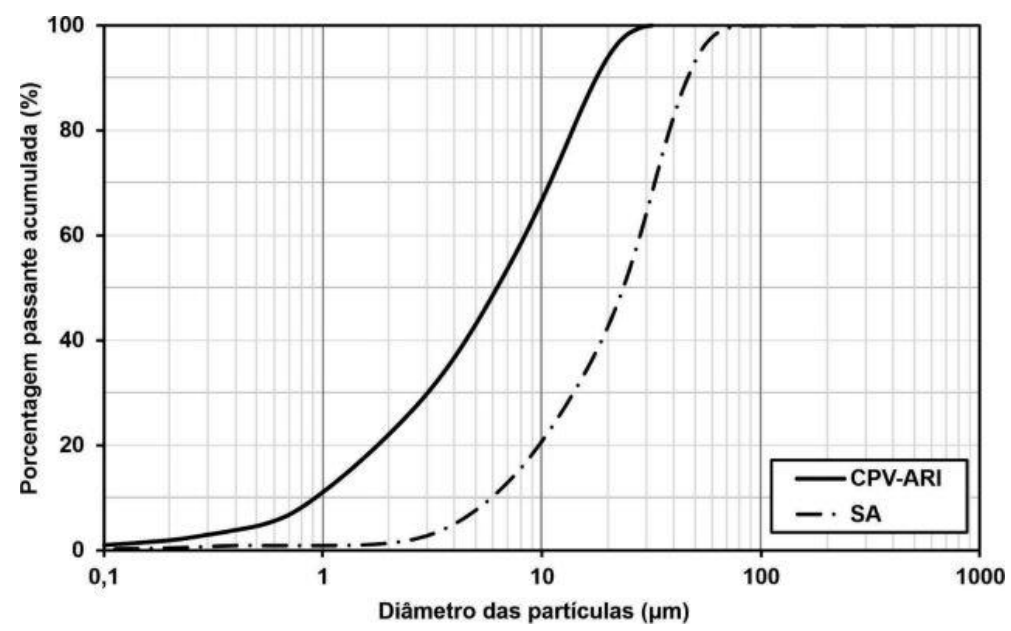

Figura 1: Distribuição granulométrica à laser do cimento CPV-ARI e da sílica ativa (SA).

As partículas de sílica ativa apresentaram diâmetro médio superior às partículas do cimento, contrariando o esperado. Segundo MEHTA e MONTEIRO [37] as partículas de sílica ativa possuem formação esférica com diâmetro médio igual a 0,1 $\mu \mathrm{m}$. Porém, DIAMOND et al. [38] e JUENGER e SIDDIQUE [22] afirmam que a sílica ativa é comercializada na forma aglomerada com o intuito de facilitar seu transporte e armazenamento, resultando em aglomerados de partículas cujo diâmetro varia de 10 a várias centenas de mícrons. Dessa maneira, com o intuito de manter as características do material comercial e sua forma de utilização em campo, optou-se por não utilizar nenhum método de dispersão no presente estudo

A sílica ativa possui massa específica igual a $1,95 \mathrm{~g} / \mathrm{cm}^{3}$, área específica igual a $20.238 \mathrm{~m}^{2} / \mathrm{kg}$ (método BET) e apresenta $2,70 \%$ de perda ao fogo. Adicionalmente, a adição mineral foi caracterizada por difratometria de raios X (Shimatzu Co. modelo XRD-7000, operando a $30 \mathrm{kV}, 30 \mathrm{~mA}$ ), considerando a variação angular de $5^{\circ}$ a $75^{\circ}$, passo de $0,02^{\circ}$ e velocidade de varredura de $2 \%$ min. A Figura 2 apresenta o difratograma da sílica ativa no estado anidro, sendo possível observar a presença de um halo amorfo, que indica o comportamento vítreo típico de pozolanas.

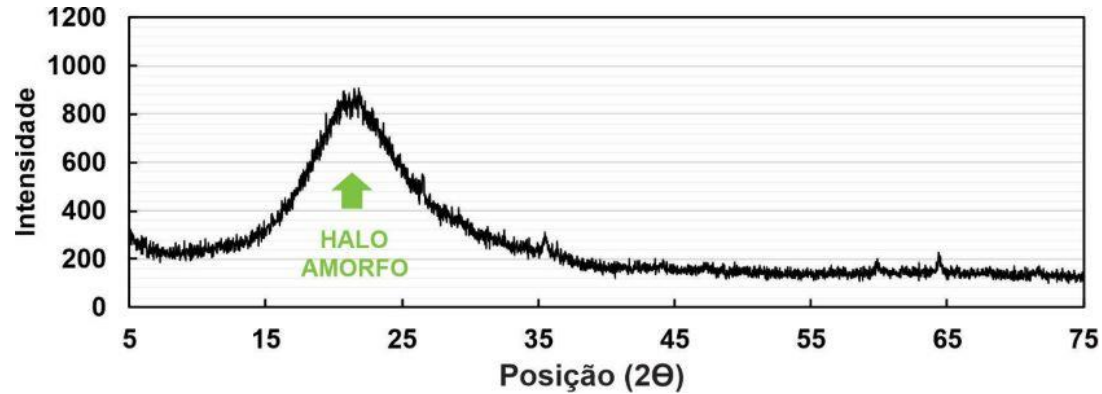

Figura 2: Difratograma da sílica ativa no estado anidro.

O ensaio Chapelle modificado foi realizado, com o intuito de investigar a reatividade da adição mineral, conforme indicado pela NBR 15895 [33]. O resultado obtido foi igual a $1542 \mathrm{mg} \mathrm{de} \mathrm{Ca}(\mathrm{OH})_{2}$ fixado por grama de sílica ativa. Este valor é superior em $253 \%$ ao limite de $436 \mathrm{mg} \mathrm{Ca}(\mathrm{OH})_{2} / \mathrm{g}$ de material, indicado por [39] como característica de um material pozolânico, confirmando a elevada capacidade de reação da sílica ativa utilizada no experimento. O trabalho de HOPPE FILHO et al. [35] corrobora com esta informação, pois os autores defendem o limite mínimo de $1100 \mathrm{mg} \mathrm{Ca}(\mathrm{OH})_{2} / \mathrm{g}$ de adição para que a pozolana testada seja considerada de alta reatividade.

\subsection{Mistura, moldagem e paralisação da hidratação}

Com o intuito de avaliar o consumo e a formação dos compostos hidratados, foram elaboradas pastas cimentícias. Os traços utilizados tiveram a substituição parcial do cimento pela sílica ativa em massa, em teores de $5,10,15$ e $20 \%$ e relação água/aglomerante (a/agl) constante, como mostra a Tabela 3. 
Tabela 3: proporção de mistura das pastas cimentícias.

\begin{tabular}{ccccc}
\hline Série & Aglomerante & Cimento $\mathbf{( k g )}$ & Sílica Ativa $\mathbf{( k g )}$ & a/agl \\
\hline REF & 1,0 & 1 & 0 & 0,58 \\
SA-5 & 1,0 & 0,95 & 0,05 & 0,58 \\
SA-10 & 1,0 & 0,90 & 0,10 & 0,58 \\
SA-15 & 1,0 & 0,85 & 0,15 & 0,58 \\
SA-20 & 1,0 & 0,80 & 0,20 & 0,58 \\
\hline
\end{tabular}

Foram moldadas 4 amostras cilíndricas de dimensões 22 x $44 \mathrm{~mm}$, por idade e por traço. A cura dos corpos de prova foi realizada imersa em água saturada com cal até as idades de análise. Para a realização dos ensaios nos corpos de prova em pasta, a hidratação foi paralisada nas idades escolhidas para análises. Para isso, as amostras foram trituradas e imersas em acetona PA por 8 horas [40]. Após a saturação, foram submetidas à secagem em temperatura de $40^{\circ} \mathrm{C}$ em estufa até a constância de massa e acondicionadas em dessecador com sílica-gel até o momento das análises.

\subsection{Acompanhamento da cinética das reações de hidratação}

A determinação da perda gravimétrica foi realizada nas pastas com o intuito de acompanhar a cinética da reação entre os produtos provenientes da hidratação do cimento e a sílica ativa, sendo realizada nas idades de 28, 69 e 105 dias de hidratação. Para tal, adotou-se uma técnica simplificada, através da utilização de um forno mufla da marca Quimis modelo Q318M24 operando com uma taxa de aquecimento de $10^{\circ} \mathrm{C} / \mathrm{min}$. A preparação da amostra consistiu em: (a) paralisação da hidratação; (b) moagem manual da pasta cimentícia em almofariz; e (c) retirada de aproximadamente $15 \mathrm{~g}$ para análise. Foram utilizadas três amostras distintas para cada série em estudo, sendo os valores apresentados posteriormente, correspondente à média das análises realizadas. Com base na massa inicial de cada amostra foram calculadas as perdas de massa, em porcentagem, subtraindo-se do valor da massa final obtida nos seguintes intervalos de temperatura: 30 a $400^{\circ} \mathrm{C}, 400$ a $600^{\circ} \mathrm{C}$ e 600 a $1000^{\circ} \mathrm{C}$, referente à perda de massa característica da decomposição do silicato de cálcio hidratado $(\mathrm{CSH})$, das fases aluminato e dos compostos de magnésio; da desidroxilação do $\mathrm{Ca}(\mathrm{OH})_{2}$; e da descarbonatação do $\mathrm{CaCO}_{3}$, respectivamente.

As diferentes composições não se apresentam na mesma base de não voláteis, sendo a massa residual de cada uma diferente após o término do ensaio. Dessa maneira, com o intuito de viabilizar a comparação entre as séries, a massa residual resultante do ensaio de perda gravimétrica em forno mufla foi normalizada para $100 \%$ e as perdas de massa corrigidas $[35,36]$.

Além disso, admitiu-se que a carbonatação nas amostras foi desprezível, visto que as pastas estando em cura saturada não tiveram contato prolongado com o meio atmosférico, a não ser durante o procedimento de moagem e armazenamento das amostras. Logo, o teor de portlandita presente na pasta em relação a perda de massa da amostra foi calculada de acordo com a Equação (1) [41].

$$
\mathrm{Ca}(\mathrm{OH})_{2}=\frac{\mathrm{MM}_{\mathrm{Ca}(\mathrm{OH})_{2}}}{\mathrm{MM}_{\mathrm{H}_{2} \mathrm{O}}} \cdot \mathrm{H}_{2} \mathrm{O}+\frac{\mathrm{MM}_{\mathrm{Ca}(\mathrm{OH})_{2}}}{\mathrm{MM}_{\mathrm{CO}_{2}}} \cdot \mathrm{CO}_{2}=4,11 \cdot \mathrm{H}_{2} \mathrm{O}+1,68 \cdot \mathrm{CO}_{2}
$$

Onde: $\mathrm{Ca}(\mathrm{OH})_{2}$ é teor de portlandita (hidróxido de cálcio, \%); $M M_{\mathrm{Ca}(\mathrm{OH})_{2}}$ é a massa molecular de hidróxido de cálcio $(74,09 \mathrm{u}) ; \mathrm{MM}_{\mathrm{H}_{2} \mathrm{O}}$ é a massa molecular da água $(18,02 \mathrm{u}) ; \mathrm{H}_{2} \mathrm{O}$ é a perda de massa percentual referente à decomposição da hidroxila entre 400 e $600^{\circ} \mathrm{C}(\%) ; M M_{\mathrm{CO}_{2}}$ é a massa molecular do anidrido carbônico $(44,01 \mathrm{u})$; e $\mathrm{CO}_{2}$ é o teor de dióxido de carbono, obtido em relação a perda de massa percentual referente à decomposição do anidrido carbônico entre 600 e $1000^{\circ} \mathrm{C}(\%)$.

O cimento utilizado (CPV - ARI) pode conter até $10 \%$ de fíler calcário. Dessa maneira, com o intuito de validar a Equação (1), o teor de portlandita remanescente foi também estimado através da titulação volumétrica. Tal procedimento consistiu na titulação de uma alíquota de aproximadamente $50 \mathrm{~mL}$ de uma solução contendo 0,50 gramas de pasta previamente paralisadas nas idades de análise e moídas, adicionadas a um recipiente Erlenmeyer plástico contendo aproximadamente $200 \mathrm{~mL}$ de água destilada por 24 horas consecutivas. A titulação das soluções de caráter essencialmente alcalino foi realizada através do emprego de ácido $\mathrm{HCl}$ (ácido clorídrico) com concentração $0,1 \mathrm{M}$ e uma solução alcoólica azul de bromotimol como indicador colorimétrico, apresentando cor azul para pH básico e sendo amarelo para pH ácido (zona de viragem de 7,6 a 6,0). Considerando que todo o hidróxido se encontra combinado como portlandita, é possível estimar o teor de portlandita remanescente através das Equações (2) e (3). 


$$
\begin{aligned}
& \mathrm{Ca}(\mathrm{OH})_{2}=\frac{\mathrm{V}_{\mathrm{AMOSTRA}} \times \mathrm{MM}_{\mathrm{Ca}(\mathrm{OH})_{2}} \times\left[\mathrm{OH}^{-}\right]}{\mathrm{m}_{\text {AMOSTRA }}} \times 100 \\
& {\left[\mathrm{OH}^{-}\right]=\frac{\mathrm{V}_{\mathrm{HCl}} \times \mathrm{C}_{\mathrm{HCl}} \times \mathrm{f}_{\mathrm{c}}}{\mathrm{V}_{\text {ALÍQUOTA }}}}
\end{aligned}
$$

Onde: $\mathrm{Ca}(\mathrm{OH})_{2}$ é teor portlandita remanescente (\%); $V_{\text {AMOSTRA }}$ é o volume da solução de diluição $(0,20 \mathrm{~L})$; $\mathrm{MM}_{\mathrm{Ca}(\mathrm{OH})_{2}}$ é a massa molar do hidróxido de cálcio $(74,093 \mathrm{~g} / \mathrm{mol}) ;\left[\mathrm{OH}^{-}\right]$a concentração de íons hidroxila $(\mathrm{mmol} / \mathrm{L}) ; m_{\text {AMOSTRA }}$ a massa da amostra em pasta $(0,50 \mathrm{gr}) ; C_{\mathrm{HCl}}$ a concentração do ácido utilizado como titulante $(0,1 \mathrm{M}) ; V_{H C l}$ é o volume de ácido consumido $(\mathrm{L}) ; f_{c}$ é o fator de correção da concentração do ácido e $V_{\text {ALíquota }}$ o volume da alíquota utilizada na titulação $(0,05 \mathrm{~L})$.

\subsection{Acompanhamento da formação de produtos em microescala}

A técnica de difração de raios-X foi realizada com o intuito de identificar a cinética das reações de hidratação e das reações pozolânicas na matriz cimentícia. Para tal, utilizou-se um aparelho da marca Shimatzu Co. modelo XRC-7000 operando a $40 \mathrm{kV}, 20 \mathrm{~mA}$. Os parâmetros de ensaio foram: ângulo de $5^{\circ}$ a $70^{\circ}$, passo de $0,02^{\circ}$ e velocidade de varredura de $1,2^{\circ} / \mathrm{min}$.

A morfologia dos cristais produzidos durante a hidratação do cimento das amostras de pastas paralisadas foi visualizada com o auxílio do microscópio eletrônico de varredura com espectroscopia de energia dispersiva (MEV-EDS), FEG SEM, Tescan, Mira 3 e microssonda analítica de raios X Oxford X-Max 50. Para o ensaio foram utilizadas peças fraturadas das amostras, com 28 e 105 dias de hidratação, fixadas em bases metálicas e metalizadas com ouro.

\section{RESULTADOS E DISCUSSÕES}

\subsection{Acompanhamento da cinética das reações de hidratação}

A utilização de métodos de análise térmicas é comumente utilizada para a estimativa da pozolanicidade das adições minerais, através da quantificação do consumo de portlandita ao longo do tempo [22]. Dessa maneira, a Tabela 4 mostra os resultados do teor remanescente de portlandita ao longo de 105 dias de hidratação, estimados através da perda de massa entre 400 a $600^{\circ} \mathrm{C}$ e admitindo-se uma carbonatação desprezível das amostras. Com o intuito de facilitar a análise dos dados, a Figura 3 apresenta o índice médio de portlandita remanescente médio para as diferentes séries nas idades de análise, ao considerar o valor da série REF como $100 \%$ (mostrado pela linha pontilhada na figura).

Tabela 4: Teor de portlandita remanescente na matriz cimentícia ao longo do tempo.

\begin{tabular}{c|cc|cc|cc}
\hline \multirow{2}{*}{ SÉRIE } & \multicolumn{2}{|c|}{$\mathbf{2 8}$ dias } & \multicolumn{2}{c|}{ 69 dias } & \multicolumn{2}{c}{ 105 dias } \\
\cline { 2 - 7 } & T. P. & E. P. & T. P. & E. P. & T. P. & E. P. \\
\hline REF & 24,69 & 0,22 & 25,49 & 0,43 & 23,68 & 0,62 \\
SA-5 & 25,00 & 3,91 & 22,08 & 0,62 & 20,85 & 0,02 \\
SA-10 & 19,01 & 0,21 & 18,51 & 0,45 & 17,86 & 0,15 \\
SA-15 & 19,88 & 4,67 & 17,13 & 0,06 & 15,94 & 0,99 \\
SA-20 & 15,58 & 1,74 & 14,25 & 0,02 & 14,76 & 0,02 \\
\hline
\end{tabular}

T. P. - Teor de portlandita (\%); E. P. - Erro padrão. 


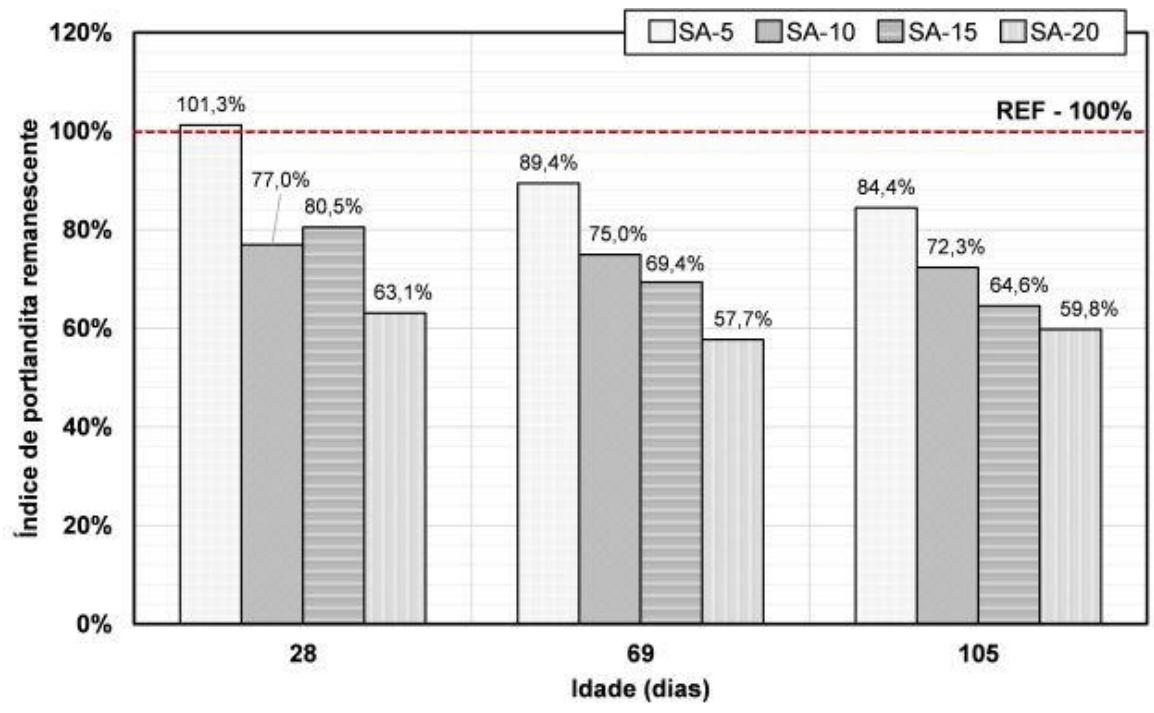

Figura 3: Índice de portlandita remanescente nas séries com sílica ativa nas diferentes idades de análise.

O teor de portlandita remanescente resulta da ação combinada da hidratação do cimento, produzindo hidróxido de cálcio, e a atividade pozolânica da sílica ativa. De acordo com MEHTA e MONTEIRO [37], para pastas de cimento com idades entre 3 e 12 meses o teor referente à quantidade de $\mathrm{Ca}(\mathrm{OH})_{2}$ é da ordem de 15 a $25 \%$, estando a amostra sem adição de sílica ativa de acordo com o indicado pelos autores. A série SA-5 apresentou índice de portlandita remanescente superior a 100\%, podendo tal comportamento ser atribuído à um aumento da hidratação do cimento [40]. Em contrapartida, as demais séries com sílica ativa apresentaram menor teor de portlandita quando comparadas a série sem adição mineral (REF) em todas as idades de análise, indicando uma redução no teor de portlandita na matriz cimentícia endurecida.

ZELIC et al. [42], ao investigarem a cinética da hidratação de pastas cimentícias contendo diferentes teores de sílica ativa, observaram que a presença de sílica ativa aumenta levemente o grau de hidratação da matriz cimentícia nas primeiras idades, servindo como pontos de nucleação para a precipitação de produtos hidratados. Os autores observaram ainda o início das reações pozolânicas após 3 dias de hidratação e sua continuidade até 28 dias. Em contrapartida, NEITHALATH et al. [40] e BHATTACHARYA e HARISH [43] observaram que a incorporação de sílica ativa em teores de substituição de até $12 \%$ reagem com o hidróxido de cálcio proveniente da hidratação do cimento já nas primeiras idades (1-3 dias). De acordo com PAPADAKIS [44], o hidróxido de cálcio dos compósitos cimentícios contendo sílica ativa é consumido desde o início da hidratação do cimento, logo, o teor de hidróxido de cálcio da matriz cimentícia passa por um ponto máximo entre $\mathrm{o} 10^{\circ} \mathrm{e} 30^{\circ}$ dia de hidratação e, posteriormente, apresenta uma diminuição conforme reação pozolânica prossegue.

Ao longo do tempo, é possível identificar uma diminuição no teor de portlandita remanescente em todas as pastas cimentícias ao comparar a primeira e a última idade de análise. Apenas a série SA-20 apresentou maior índice de portlandita remanescente aos 105 dias, quando comparada ao valor obtido aos 69 dias de hidratação. Porém, por meio da análise estatística Two-way ANOVA, considerando 5\% de significância, apenas o teor de sílica ativa possui influência no teor de portlandita, não sendo possível identificar uma redução de portlandita estatisticamente significativa ao longo do tempo de análise no presente estudo. Dessa maneira, é possível determinar o valor médio de portlandita para cada composição após 105 dias de hidratação, sendo igual a $24,62 \%, 22,64 \%, 18,46 \%, 17,65 \%$ e $14,86 \%$ para $0,5,10,15$ e $20 \%$ de adição mineral, respectivamente. Aplicando a análise de variância múltipla (teste de Tukey) aos teores médios de portlandita obtidos, com 5\% de significância, todas as composições apresentaram diferença estatística entre si.

Em todas as pastas investigadas, o teor médio de portlandita remanescente apresentou valores menores que o da pasta sem adição mineral (REF), indicando a redução do teor de hidróxido de cálcio na matriz cimentícia endurecida, assim como observado no estudo realiazdo por BHATTACHARYA e HARISH [43], RÊGO et al. [27]; JEONG et al. [45]. A amostra com 20\% de sílica ativa foi a que apresentou menor teor médio de portlandita remanescente, sendo aproximadamente $40 \%$ menor do que a quantidade presente na série de referência. As composições com 5,10 e $15 \%$ de sílica ativa apresentaram uma redução de aproximadamente 8,25 e $28 \%$ em relação a série sem adição mineral (REF), respectivamente. Adicionalmente, o teor médio de hidróxido de cálcio das pastas contendo sílica ativa diminui com o aumento do nível de substituição 
da sílica ativa, seguindo uma tendência com coeficiente de regressão linear igual a 0,885 , como mostra a Figura 4.

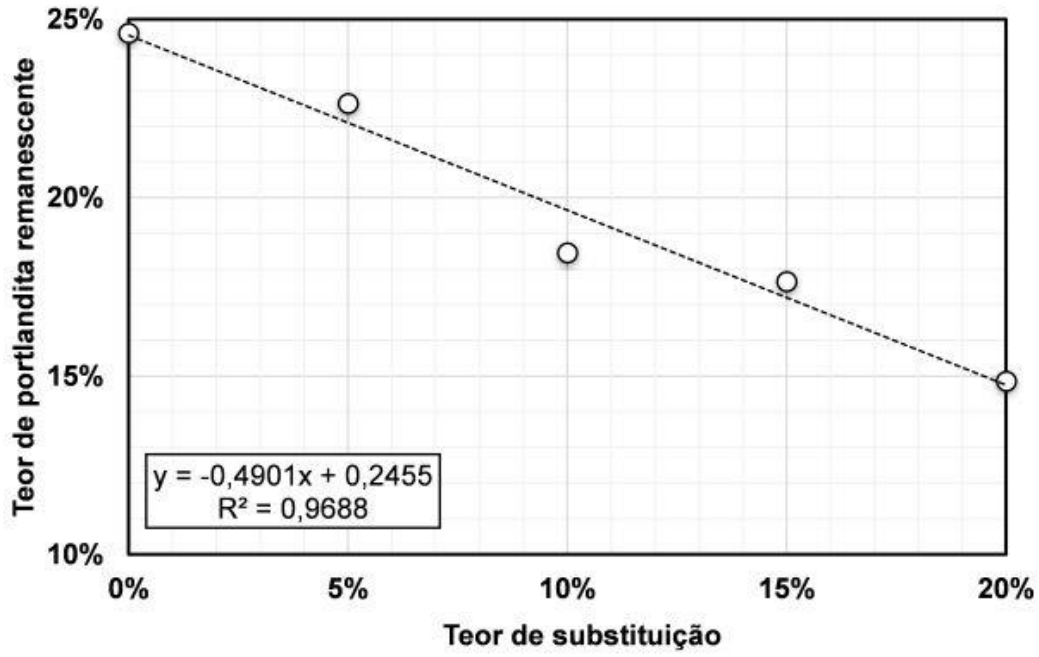

Figura 4: Correlação entre o teor de substituição de cimento por sílica e o teor médio de portlandita remanescente.

De maneira semelhante, UZBAS e AYDIN [14] observaram uma relação linear entre a utilização da sílica ativa como composição do aglomerante e a diminuição do teor de portlandita em pastas cimentícias com relação água/cimento igual a 0,60, em diferentes idades de hidratação (7, 28 e 90 dias). Tal comportamento pode ser atribuído ao efeito de diluição, devido ao menor teor de cimento na matriz cimentícia, e a depleção de hidróxido de cálcio promovida pela ação da atividade pozolânica e a consequente formação de compostos hidratados secundários.

Com o intuito de compreender melhor o efeito da sílica ativa e considerando que as amostras estiveram sob a mesma condição de exposição durante toda a duração dos ensaios, através de uma análise simplificada, é possivel estimar, de maneira quantitativa, o consumo médio de hidróxido de cálcio proveniente da atividade pozolânica da sílica ativa, como realizado por HOPPE FILHO et al. [36]. A Figura 5 apresenta o consumo médio de portlandita pelas composições, sendo o teor teórico de portlandita determinado a partir da proporção de cimento utilizada nas composições com sílica ativa em relação a série REF, o teor médio de portlandita remanescente obtido por meio do ensaio de perda gravimétrica no forno mufla e sua diferença em relação ao teor teórico igual ao teor de portlandita consumido pelas reações pozolânicas.

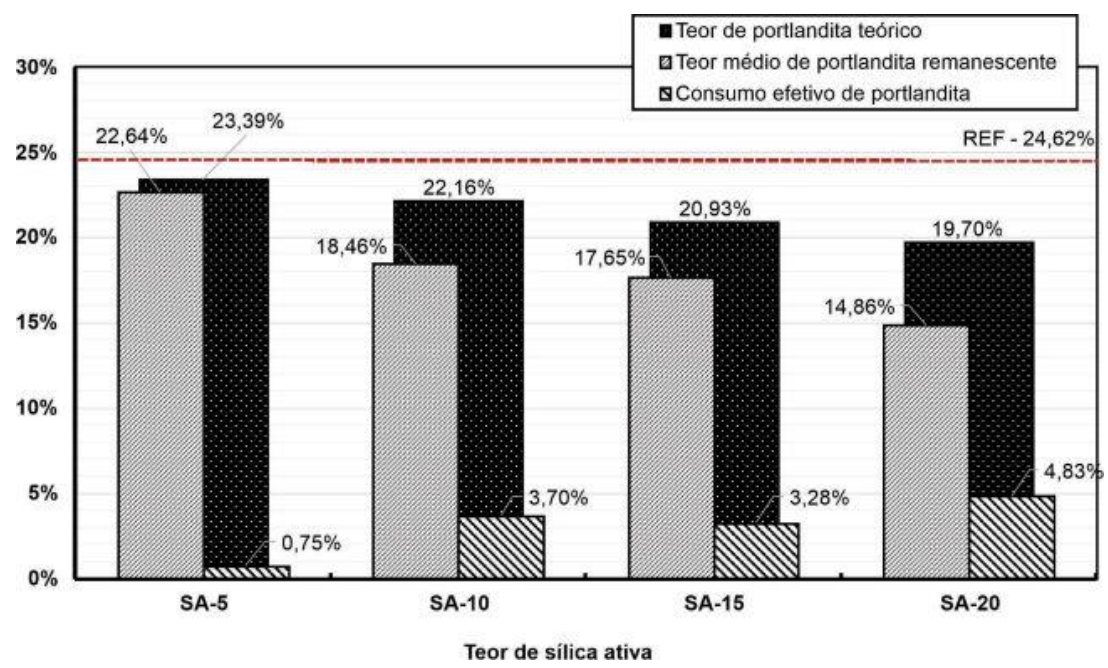

Figura 5: Teor teórico de portlandita disponível na pasta, teor médio de portlandita remanescente e consumo médio de portlandita pela atividade pozolânica. 
A partir da análise realizada, é possível observar o consumo médio de portlandita pela atividade pozolânica em todas as séries contendo sílica ativa. A matriz cimentícia com 5\% de sílica ativa apresentou menor consumo de portlandita, sendo o consumo médio igual a 1,55\% em relação ao teor de portlandita teórico, seguida da série SA-10, SA-15 e SA-20, com consumos médios de 3,70\%, 3,28\% e 4,83\%, respectivamente. RÊGO et al. [27] afirmam que a reatividade pozolânica da sílica ativa é afetada por sua área especifíca superficial, pela temperatura do ensaio e pela quantidade de material utilizado. Considerando a utilização da mesma sílica ativa em todas as pastas cimentícias e as mesmas condições de ensaio, é possível observar uma tendência linear entre o teor de sílica ativa e o consumo de hidróxido de cálcio com coeficiente de regressão linear igual a 0,885 , como mostra a Figura 6. Dessa maneira, quanto maior o teor de substituição parcial do cimento por sílica ativa, maior é o consumo proveniente da sua atividade pozolânica.

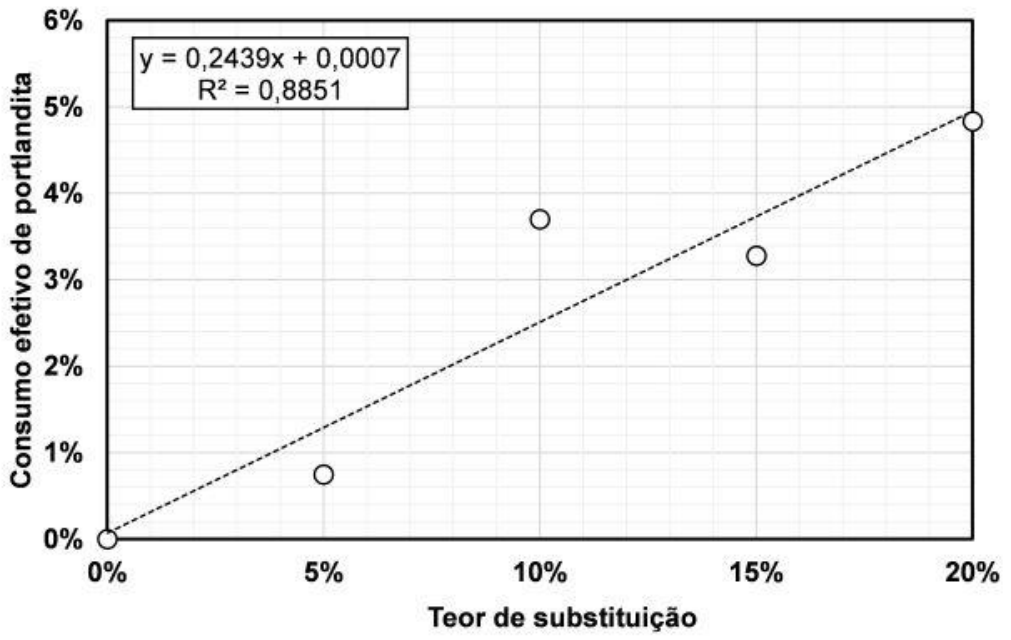

Figura 6: Correlação entre o teor de substituição de cimento por sílica e consumo percentual de portlandita.

Por fim, com o intuito de validar os resultados obtidos por meio da análise de perda de massa em forno mufla, o teor de portlandita remanescente foi, adicionalmente, estimado através da titulação química (Tabela 5). A Figura 7 mostra os resultados obtidos através de ambas as técnicas nas amostras após 28 dias de hidratação.

Tabela 5: Teor de portlandita remanescente aos 28 dias de hidratação por meio de titulação química.

\begin{tabular}{ccc}
\hline Série & Teor de portlandita (\%) & E. P. \\
\hline REF & 25,13 & 0,25 \\
SA-5 & 20,66 & 0,00 \\
SA-10 & 19,16 & 0,52 \\
SA-15 & 15,66 & 0,39 \\
SA-20 & 16,28 & 0,34 \\
\hline E. P. - Erro padrão & \\
\hline
\end{tabular}




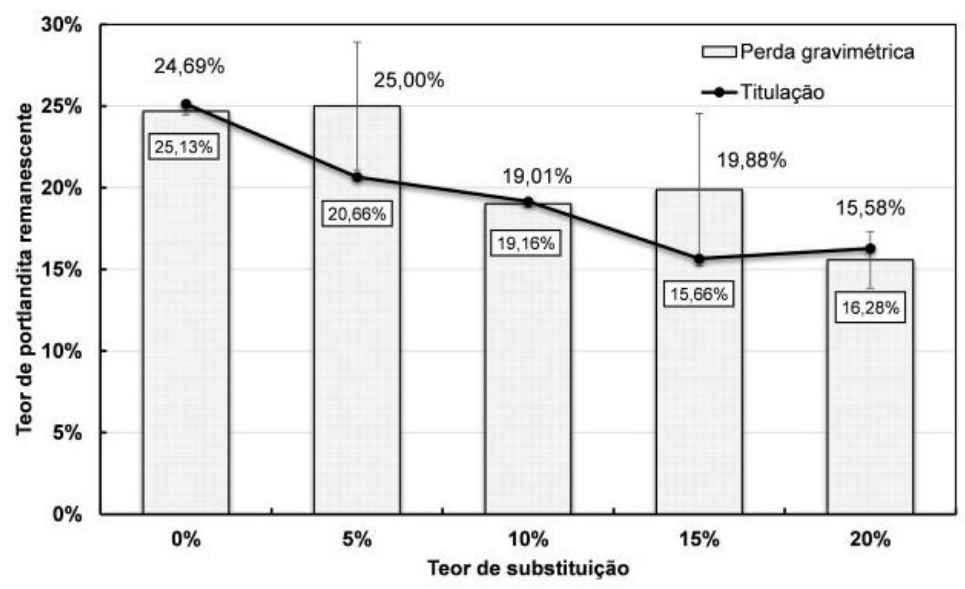

Figura 7: Comparação entre as técnicas utilizadas para estimativa do teor de portlandita remanescente aos 28 dias de hidratação.

Na maioria das séries, o teor de portlandita remanescente estimado através da titulação química mostrou-se semelhante ao método de perda de massa em forno mufla, porém, é possível observar uma discrepância de valores para as séries contendo 5 e $15 \%$ de sílica ativa, devido à grande variabilidade dos dados obtidos através da perda gravimétrica. Por meio da análise estatística One-way ANOVA, considerando 5\% de significância, os resultados obtidos para cada série, utilizando ambas as técnicas, mostraram-se estatisticamente semelhantes. Dessa maneira, considerou-se que os resultados obtidos através da perda de massa em forno mufla foram representativos para a caracterização da matriz cimentícia no que tange à reserva alcalina do meio em relação ao teor de portlandita remanescente após um determinado período de hidratação.

A determinação dos teores de portlandita consumidos por atividade pozolânica permite estimar o consumo de hidróxido de cálcio efetivo por unidade de massa de adição mineral na pasta. A série contendo 5\% de sílica ativa apresentou uma fixação média de $310 \mathrm{mg}$ de $\mathrm{Ca}(\mathrm{OH})_{2} / \mathrm{g}$ de sílica ativa, seguido de 370,249 e $341 \mathrm{mg}$ de $\mathrm{Ca}(\mathrm{OH})_{2} / \mathrm{g}$ de sílica ativa para as séries com 10, 15 e $20 \%$ de sílica ativa, respectivamente. Considerando que o teor de hidróxido de cálcio fixado é uma propriedade do material, o consumo médio efetivo de hidróxido de cálcio pela sílica ativa é igual a 317,5 $\mathrm{mg} \mathrm{de} \mathrm{Ca}(\mathrm{OH})_{2} / \mathrm{g}$ de adição. Como o teor de hidróxido de cálcio consumido no ensaio Chapelle modificado é $1542 \mathrm{mg}$ de $\mathrm{Ca}(\mathrm{OH})_{2} / \mathrm{g}$ de adição, tem-se que o consumo efetivo de hidróxido de cálcio é aproximadamente $80 \%$ menor do que o obtido experimentalmente. De maneira semelhante, HOPPE FILHO et al. [36] obtiveram diferentes valores de fixação de hidróxido de cálcio para pastas cimentícias com a incorporação de diferentes adições pozolânicas em um teor de $35 \%$ (em volume) e relação água/aglomerante de 0,70 , ao utilizar a análise termogravimétrica, sendo o consumo efetivo de hidróxido de cálcio $61,3 \%$ menor para a sílica ativa, $65,5 \%$ para o metacaulim e $72 \%$ para a sílica de casca de arroz quando comparado aos valores obtidos através do ensaio Chapelle modificado.

O método Chapelle modificado é um procedimento realizado em solução aquosa com hidróxido de cálcio, logo, o contato da portlandita com a superfície dos grãos reativos da sílica ativa ocorre de modo facilitado. Além disso, o ensaio garante a solubilização da matriz amorfa da pozolana, devido a permanência da reserva alcalina até o final do procedimento, resultando otimização da sua reatividade. Porém, SNELLINGS e SCRIVENER [46], ao analisar os produtos precipitados durante a aplicação do método Chapelle para estimativa do potencial reativo de diversas adições reativas, observaram a formação de calcita, proveniente da reação do hidróxido de cálcio com o dióxido de carbono presente na atmosfera, superestimando o resultado obtido ao final do procedimento. No caso dos compósitos cimentícios, a solubilidade do hidróxido de cálcio é maior do que nos métodos que utilizam temperaturas elevadas [32], porém, a mobilidade iônica é muito mais restrita devido a formação das fases sólidas, resultando em um potencial de reação pozolânica não desenvolvido em sua plenitude, mesmo em condições ótimas, como a cura úmida prolongada aplicada neste trabalho.

Adicionalmente, a Figura 6 mostra imagens de MEV-EDS evidenciando a ocorrência de partículas não reagidas na matriz cimentícia, com formação esférica e ricas em $\mathrm{Si} \mathrm{e}_{2}(85 \%)$, tratando-se de partículas de sílica ativa. Além disso, o diâmetro médio das partículas de sílica ativa é de $0,1 \mu \mathrm{m}$, sendo as formações identificadas cerca de 100 (Figura 8a) e 200 vezes maior (Figuras 8b, 8c e 8d), de modo que argumenta-se que são aglomerados do material. 


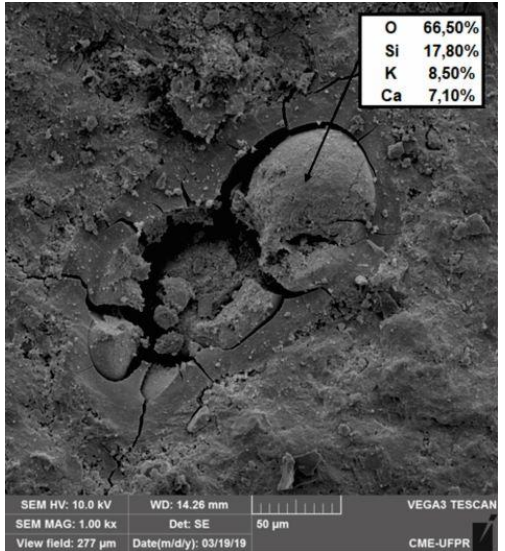

(a)

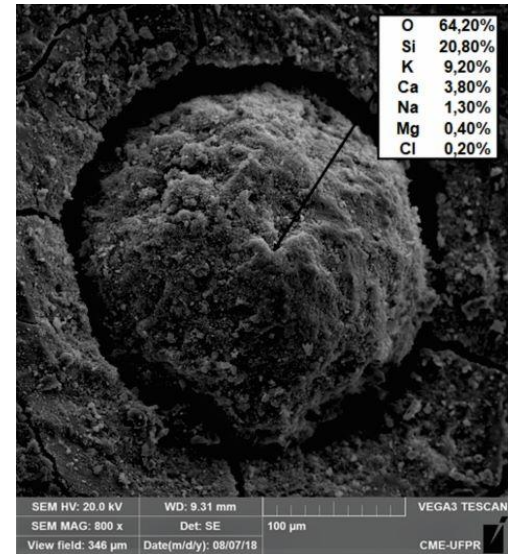

(b)

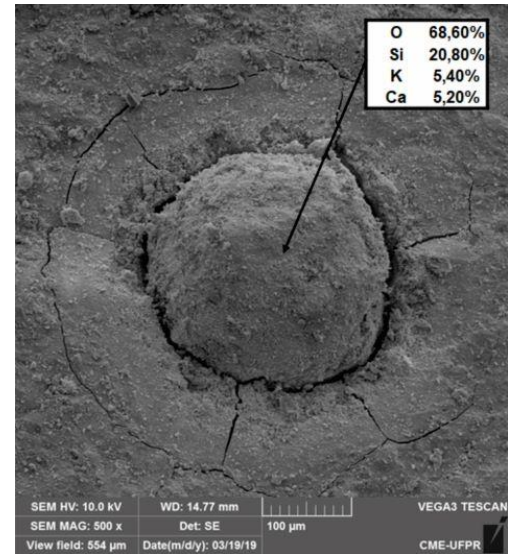

(c)

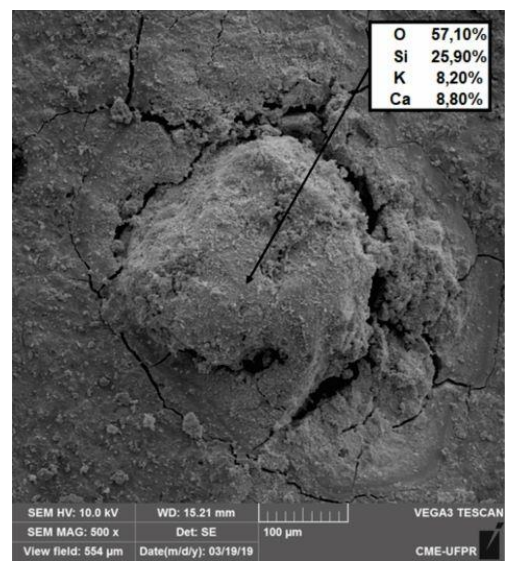

(d)

Figura 8: Imagem de aglomerado de partículas de sílica ativa em amostra com 5\% (a), 10\% (b), $15 \%$ (c) e $20 \%$ (d) de substituição aos 28 dias de hidratação.

Analogamente, MITCHELL et al. [47] observaram a presença de aglomerados de sílica ativa parcialmente reagidos em pastas cimentícias contendo $20 \%$ da adição mineral em substituição parcial do cimento e relação água/aglomerante igual a 0,50 após 180 dias de hidratação, apesar de aproximadamente $75 \%$ da adição ser consumida nos primeiros 90 dias de hidratação. Tal fato resultou em efeitos adversos na trabalhabilidade das pastas cimentícias frescas estudadas por WANG et al. [48], resultando em uma menor atividade pozolânica e uma menor resistência mecânica do compósito. Em argamassas e concretos, os aglomerados de sílica ativa tendem a ser protegidos pelos grãos de areia durante a mistura, propiciando a permanência dos aglomerados parcialmente intactos [38]. Considerando o papel da área superficial específica da sílica ativa em sua reatividade, corrobora-se a consideração realizada anteriormente, em que o potencial de reação da sílica ativa através do ensaio Chapelle modificado não é precisamente correto para os compósitos cimentícios endurecidos, devendo ser considerada a elevada resistência de dispersão do material aglomerado quando adicionado à matriz cimentícia e a consequente diminuição na velocidade das reações pozolânicas.

Por fim, QUARCIONI et al. [34] afirmam que a quantificação do efeito químico promovido pela substituição parcial do cimento por um material pozolânico deve considerar o teor real de fase vítrea e sua reatividade efetiva, visto que os materiais pozolânicos são compostos por uma fase cristalina inerte e uma fase vítrea. Sendo assim, o método Chapelle modificado, que consta na norma brasileira e foi utilizado no presente estudo, não assegura o potencial de reatividade da sílica ativa quando incorporada a pastas cimentícias. Logo, mostra-se necessária a combinação de outros métodos para a quantificação da reatividade efetiva da sílica ativa, como: (a) método de DRX com refinamento Rietveld para a determinação percentual da fase amorfa do material pozolânico, responsável pelo consumo de hidróxido de cálcio, assim como realizado por CORDEIRO et al. [49] para a cinza de casca de arroz; (b) métodos que avaliam quantitativamente e qualitativamente o consumo de hidróxido de cálcio no compósito cimentício endurecido e a detecção dos produtos secundários. 


\subsection{Acompanhamento da formação de produtos em microescala}

De maneira complementar à análise de perda gravimétrica realizada, a Figura 9 apresenta os difratogramas obtidos para as composições do presente estudo após 105 dias de hidratação. Nas pastas com e sem adição de sílica ativa foram identificados picos referentes à portlandita $\left(\mathrm{Ca}(\mathrm{OH})_{2}\right)$, à calcita e ao silicato de cálcio hidratado (CSH). A identificação dos picos característicos das formações cristalinas de portlandita, após 105 dias de hidratação, corrobora o apresentado pela análise de perda gravimétrica, sendo fundamental para a análise da reatividade das adições minerais.

Apesar de todas as séries apresentarem as mesmas estruturas cristalinas, é possivel observar uma diminuição na intensidade dos picos referentes à portlandita com o aumento do teor de sílica ativa. Tal comportamento fica evidente com a análise comparativa referente aos picos de maior intensidade da portlandita $\left(17,96^{\circ} 2 \theta ; 34,1^{\circ} 2 \theta\right)$, apresentado nas Figuras $10 \mathrm{a}$ e $10 \mathrm{~b}$.

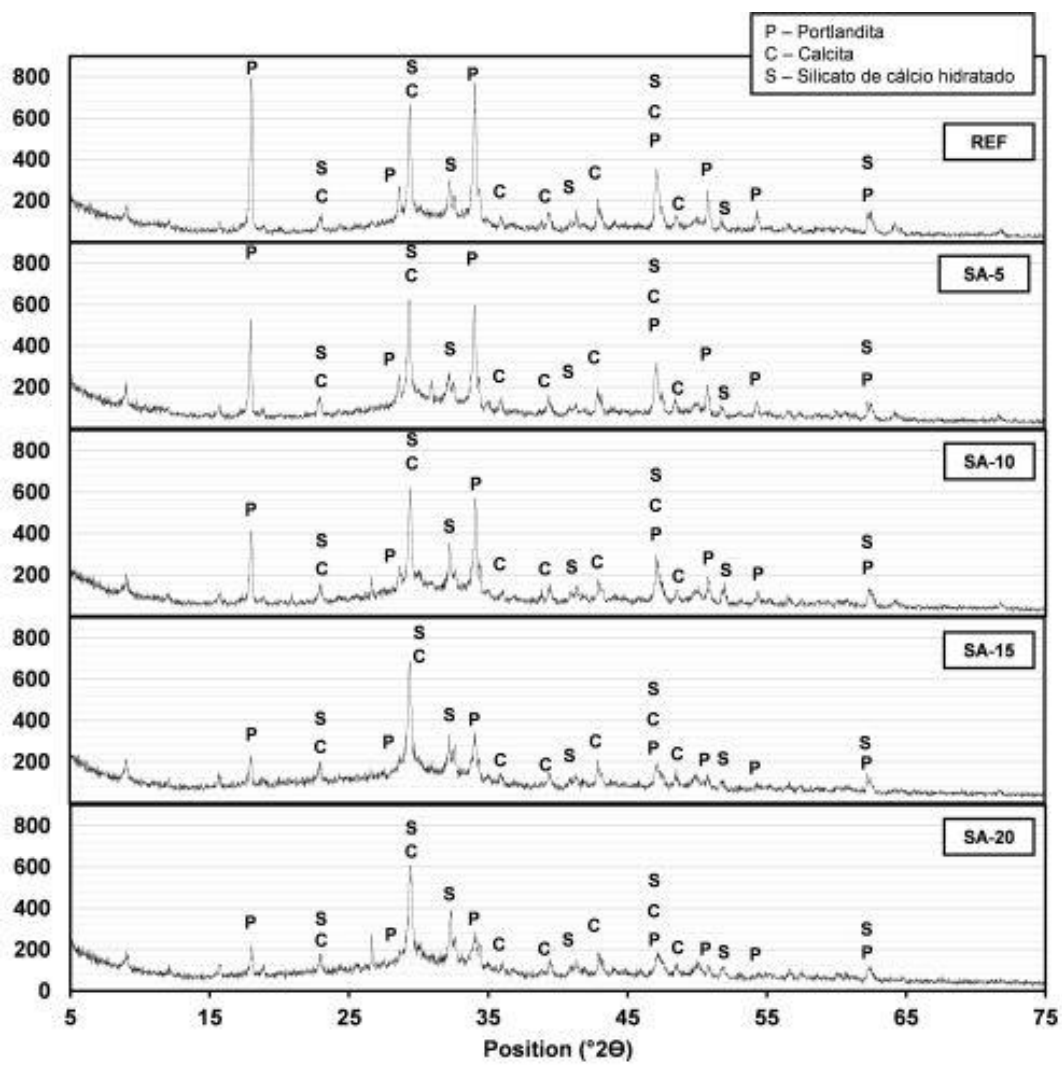

Figura 9: Difratogramas das pastas cimentícias após 105 dias de hidratação 


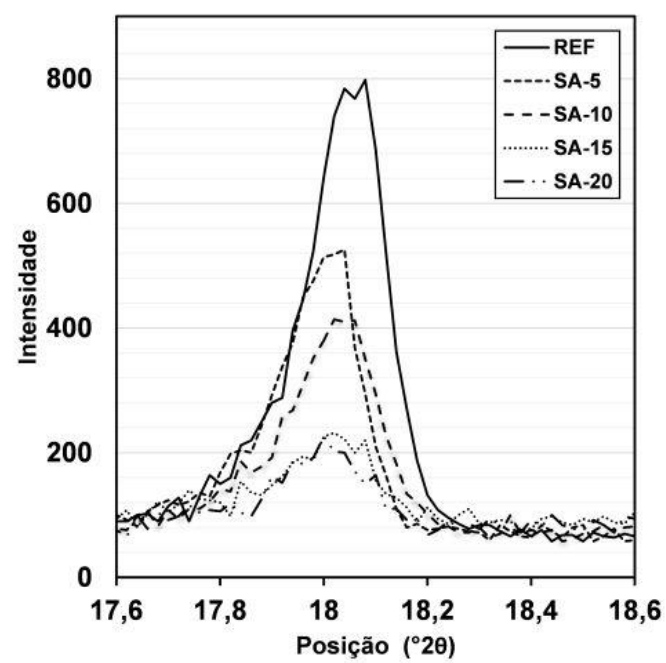

(a)

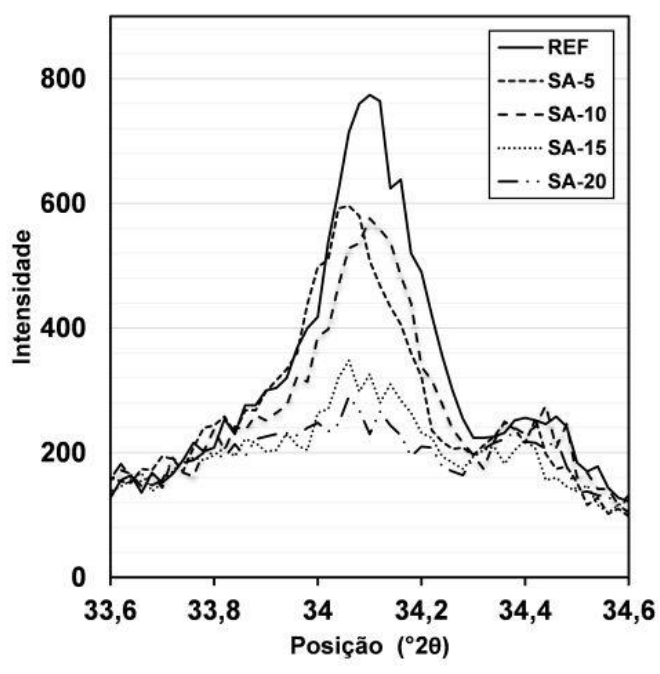

(b)

Figura 10: Difratograma de comparação da intensidade de picos isolados de portlandita remanescente nas diferentes amostras com sílica ativa após 105 dias de hidratação: $17,96^{\circ} 2 \theta$ (a); 34,1²0 (b).

Os sistemas pozolânicos contendo sílica ativa apresentaram uma diminuição nos picos referentes à estrutura cristalina da portlandita nas pastas cimentícias contendo sílica ativa em relação à pasta sem adição mineral. Através da análise comparativa da intensidade dos picos presentes nos difratogramas de raios-X, é possível identificar uma diminuição da quantidade de portlandita com o aumento do teor de adição utilizado, sendo tal comportamento atríbuido há diminuição do cimento na matriz cimentícia e o consumo do hidróxido de cálcio pela atividade pozolânica da sílica ativa [5, 50-52].

A Figura 11 apresenta compostos identificados como portlandita nas pastas cimentícias com e sem adição de sílica ativa, com o auxílio da microscopia eletrônica de varredura com energia dispersiva por raiosx (MEV-EDS). Analisando a proporção dos elementos constituintes da portlandita $(54,0 \% \mathrm{Ca}, 43,2 \% \mathrm{O}$ e $2,80 \% \mathrm{H}$ ) percebe-se que há uma diferença significativa no teor de cálcio encontrado nos compostos presentes nas imagens obtidas, entretanto, tal diferença não descaracteriza sua presença. Tal diferença é explicada pelo efeito de borda do EDS e o pequeno tamanho do elemento ao qual o feixe de elétrons foi direcionado, sendo indica a presença de algum outro composto na região próxima à portlandita pela captação dos elétrons.

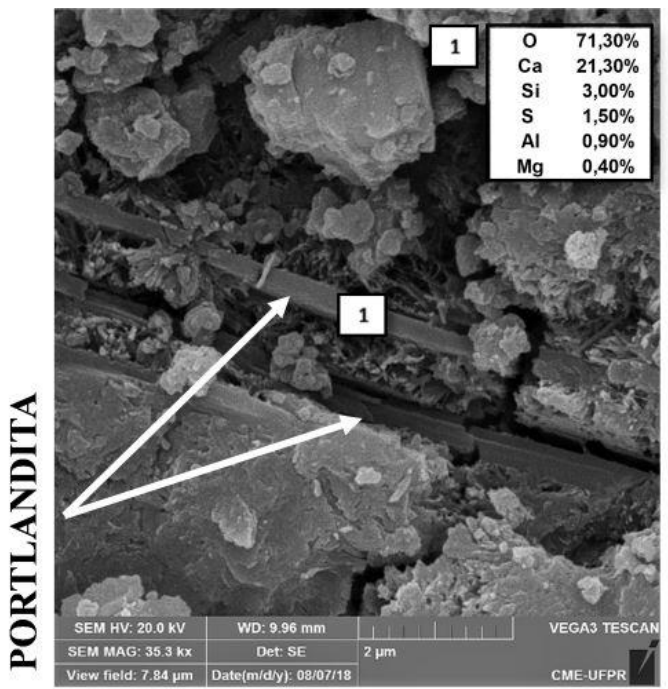

(a)

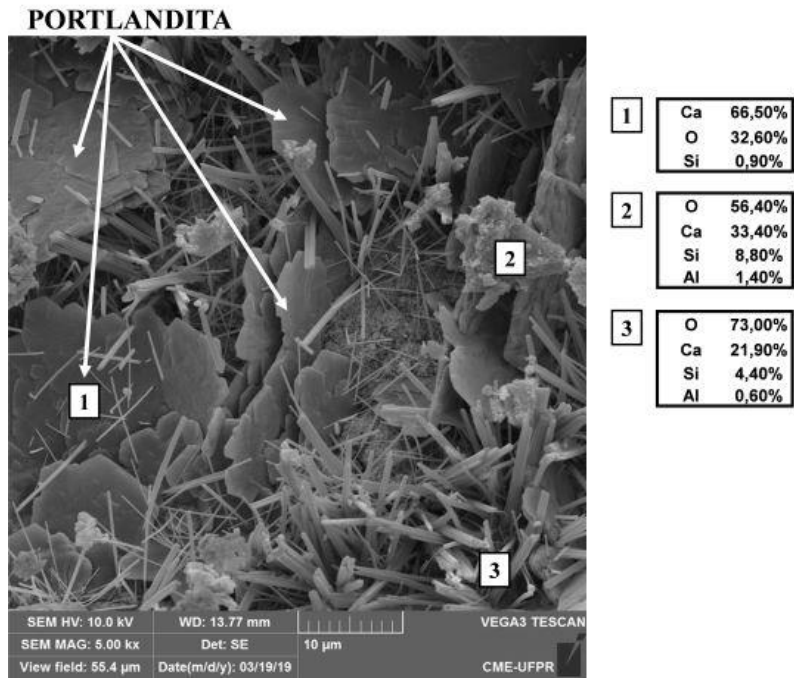

(b) 


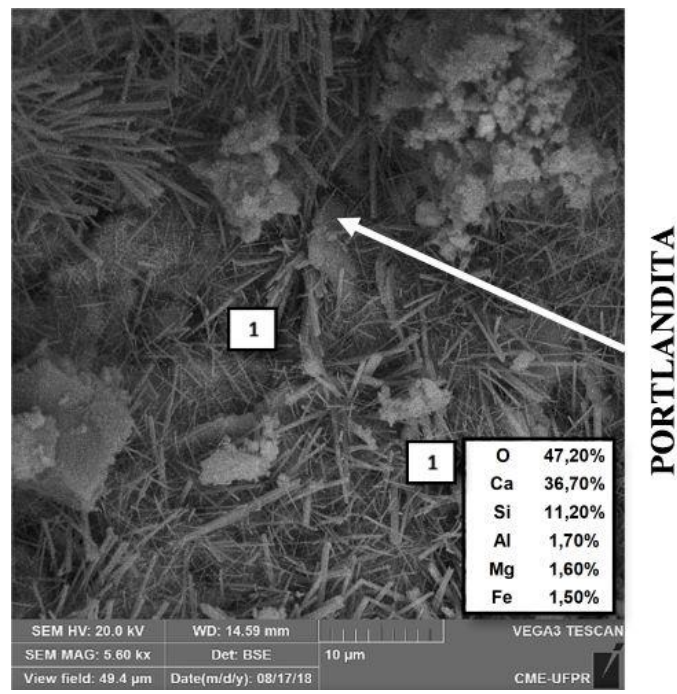

(c)

Figura 11: Imagens de MEV da matriz cimentícia referência, ou seja, sem adição mineral (a); da matriz cimentícia contendo 5\% de sílica ativa (b) e da matriz cimentícia contendo $10 \%$ de sílica ativa (c).

Segundo ROSSEN et al. [53], as pastas cimentícias sem adição mineral apresentam a portlandita majoritariamente na forma de massas densificadas e poucas placas, como indicado na Figura 11a. As Figura 11b e 11c mostram a formação do composto hidratado em uma matriz cimentícia contendo 5 e $10 \%$ de sílica ativa, respectivamente, sendo possível observar a predominância morfológica de placas, assim como observado nas imagens obtidas por CASCUDO et al. [54]. Dessa maneira, constatou-se que a utilização das adições minerais na composição do aglomerante em substituição parcial ao cimento, promove alterações microestruturais no que tange à morfologia dos compostos hidratados. Cabe ressaltar que os aglomerados de sílica ativa reagem in situ com os hidratos do cimento, formando produtos que preenchem o espaço dentro dos limites originais dos aglomerados e promovem o refinamento dos poros [38], explicando a presença de silício (Si) em todos os pontos de análise com EDS.

\section{CONCLUSÃO}

O trabalho experimental apresentado neste documento dá suporte às conclusões a seguir:

(a) $\mathrm{O}$ ensaio de perda gravimétrica mostrou que nenhum dos teores de substituição parcial do cimento Portland por sílica ativa foi capaz de esgotar a quantidade de portlandita nas pastas estudadas, havendo uma inércia para a ocorrência de reação completa por parte da sílica ativa nas condições reais das pastas cimentícias endurecidas;

(b) A análise da perda gravimétrica realizada em forno mufla mostrou resultados representativos em relação ao teor de portlandita remanescente ao longo do tempo, mesmo desconsiderando a presença de fíler calcário no cimento;

(c) O consumo efetivo de hidróxido de cálcio foi aproximadamente $80 \%$ menor do que o obtido experimentalmente pelo ensaio Chapelle modificado;

(d) O ensaio Chapelle modificado não representou de forma efetiva a atuação pozolânica da sílica ativa nos compósitos cimentícios, visto que existe uma menor mobilidade iônica na matriz cimentícia endurecida quando comparada com uma solução aquosa. Além disso, através das imagens de MEVEDS foi possível observar a presença de aglomerações do material após 105 dias de cura, justificando a diminuição da reatividade da sílica ativa utilizada no presente estudo;

(e) A morfologia da portlandita na matriz cimentícia é alterada pela sílica ativa, sendo predominantemente encontrada na forma de placas quando há a presença da adição mineral.

\section{AGRADECIMENTOS}

Os autores agradecem pela infraestrutura concedida ao desenvolvimento deste trabalho pelo Centro de Estudos em Engenharia Civil (CESEC-UFPR), pelo Programa de Pós-Graduação em Engenharia de Construção Civil (PPGECC) da Universidade Federal do Paraná (UFPR). Também agradecemos pela bolsa de estudos 
concedida pela Fundação CAPES.

\section{BIBLIOGRAFIA}

[1] BAJPAI, R., CHOUDHARY, K.,SRIVASTAVA, A., et al."Environmental impact assessment of fly ash and silica fume based geopolymer concrete," Journal of Cleaner Production, v. 254, 2020.

[2] CZARNECKI, L., WOYCIECHOWSKI, P., ADAMCZEWSKI, G. "Risk of Concrete Carboantion with Mineral Industrial By-products," KSCE Journal of Civil Engineering, v. 22, n. 2, pp. 755-764, 2018.

[3] ISAIA, G.C., ZERBINO, R.L., GASTALDINI, A.L.G., et al." "Viabilidade do emprego de cinza de casca de arroz natural em concreto estrutural (parte II): durabilidade," Ambiente Construído, v. 17, n. 2, pp. $233-$ 252, 2017.

[4] MEDEIROS, M.H.F., GOBBI, A., GROENWOLD, J., et al. "High strength reinforced concrete with metakaolin and silica fume in marine environment: an experimental work," Hormigón y Acero, v. 63, pp. 5766, 2012.

[5] MEDEIROS, M.H.F., RAISDORFER, J.W., HOPPE FILHO, J. "Influência da sílica ativa e do metacaulim na velocidade de carbonatação do concreto: relação com resistência, absorção e relação a/c," Ambiente Construído, v. 17, n. 4, pp. 125-139, 2017.

[6] PANESAR, D.K., ZHANG, R. "Performance comparison of cement replacing materials in concrete: Limestone fillers and supplementary cementing materials - A review," Construction and Building Materials, v. 251,2020 .

[7] SANJUÁN, M.Á., ARGIZ, C., GÁLVEZ, J.C., et al. "Effect of silica fume fineness on the improvement of Portland cement strength performance," Construction and Building Materials, vol. 96, pp. 55-64, 2015.

[8] SAHOO, K.K., SARKAR, P., DAVIS, R. "Mechanical properties of silica fume concrete designed as per construction practice," Proceedings of the Institute Civil Engineers - Construction Materials, v. 172, n. 1, pp. 20-28, 2019.

[9] BENLI, A. "Mechanical and durability properties of self-compacting mortars containing binary and ternary mixes of fly ash and silica fume," Structures of Concrete, n. October 2018, pp. 1096-1108, 2019.

[10] KHAN, M., ALI, M. "Improvement in concrete behavior with fly ash, silica-fume and coconut fibres," Construction and Building Materials, v. 203, pp. 174-187, 2019.

[11] KHAN, M., REHMAN, A., ALI, M. "Efficiency of silica-fume content in plain and natural fiber reinforced concrete for concrete road," Construction and Building Materials, v. 244, pp. 1-12, 2020.

[12] LUO, T., ZHOU, Y., WANG, Q. "Influence of ultra-fine slag and silica fume on properties of highstrength concrete," Magazine of Concrete Research, v. 72, n. 12, pp. 610-621, 2020.

[13] PRADHAN D., DUTTA, D. "Influence of Silica Fume on Normal Concrete," International Journal of Engineering Research and Applications, v. 3, n. 5, pp. 79-82, 2013.

[14] UZBAS, B., AYDIN, A.C. "Microstructural Analysis of Silica Fume Concrete with Scanning Electron Microscopy and X-Ray Diffraction," Engineering, Technology \& Applied Science Research, v. 10, n. 3, pp. 5845-5850, 2020.

[15] SASANIPOUR, H., ASLANI, F., TAHERINEZHAD, J. "Effect of silica fume on durability of selfcompacting concrete made with waste recycled concrete aggregates," Construction and Building Materials, v. 227 , pp. 1-12, 2019.

[16] JO, B.W., CHAKRABORTY, S., LEE, S.T., et al. "Durability Study of Silica Fume-mortar exposed to the Combined Sulfate and Chloride-rich Solution," KSCE Journal of Civil Engineering, v. 23, n. 1, pp. $356-$ 366,2019

[17] KARTHIK PRABHU, T., SUBRAMANIAN, K., JAGADESH, P., et al. "Durability properties of fly ash and silica fume blended concrete for marine environment," Indian Journal of Geo-Marine Science, v. 48, n. 11, pp. 1803-1812, 2019.

[18] KIM, S.S., QUDOOS, A., JAKHRANI, S.H., et al. "Influence of coarse aggregates and Silica Fume on the mechanical properties, durability, and microstructure of concrete," Materials (Basel)., v. 12, n. 20, 2019.

[19] GRUSZCZYŃSKI, M., LENART, M. "Durability of mortars modified with the addition of amorphous aluminum silicate and silica fume," Theoretical and Applied Fracture Mechanics, v. 107, n. October 2019, 2020. 
[20] ADIL, G., KEVERN, J.T., MANN, D. "Influence of silica fume on mechanical and durability of pervious concrete," Construction and Building Materials, v. 247, 2020.

[21] ROSSIGNOLO, J.A. "Avaliação da zona de transição interfacial pasta-agregado leve em concretos com sílica ativa e látex SBR," Matéria (Rio Janeiro), v. 12, n. 3, pp. 532-540, 2007.

[22] JUENGER, M.C.G., SIDDIQUE, R. "Recent advances in understanding the role of supplementary cementitious materials in concrete," doi: 10.1016/j.cemconres.2015.03.018. Cement and Concrete Research, v. 78, pp. 71-80, 2015.

[23] NEŽERKA, V., BÍLÝ, P., HRBEK, V., et al."Impact of silica fume, fly ash, and metakaolin on the thickness and strength of the ITZ in concrete," Cement and Concrete. Composites, v. 103, n. January, pp. 252-262, 2019.

[24] KRAMAR, S., DUCMAN, V. "Evaluation of ash pozzolanic activity by means of the strength activity index test, frattini test and DTA/TG analysis," Tehnicki Vjesnik, v. 25, n. 6, pp. 1746-1752, 2018.

[25] CARNEIRO, L.R.S., GARCIA, D.C.S., COSTA, M.C.F., et al. "Evaluation of the pozzolanicity of nanostructured sol-gel silica and silica fume by electrical conductivity measurement," Construction and Building Materials, v. 160, pp. 252-257, 2018.

[26] RAMANATHAN, S., MOON, H., CROLY, M., et al. "Predicting the degree of reaction of supplementary cementitious materials in cementitious pastes using a pozzolanic test," Construction and Building Materials, v. 204, pp. 621-630, 2019.

[27] RÊGO, J.H.S., ROJAS, M.F., TERRADES, A.M., et al. "Effect of partial substitution of highly reactive mineral additions by Nanosilica in cement pastes," Journal of Materials in Civil Engineerig, v. 31, n. 1, pp. $1-11,2019$.

[28] WANG, X., HUANG, J., DAI, S., et al. "Effect of silica fume particle dispersion and distribution on the performance of cementitious materials: A theoretical analysis of optimal sonication treatment time," Construction and Building Materials, v. 212, pp. 549-560, 2019.

[29] MENDOZA, O., TOBÓN, J.I. "An alternative thermal method for identification of pozzolanic activity in $\mathrm{Ca}(\mathrm{OH}) 2$ /pozzolan pastes," Journal of Thermal Analysis and Calorimetry, v. 114, n. 2, pp. 589-596, 2013.

[30] FERRAZ, E., ANDREJKOVIČOVÁ, S., HAJJAJI, W., et al. "Pozzolanic activity of metakaolins by the French standard of the modified Chapelle test: A direct methodology," Acta Geodynamica et Geomaterialia, v. 12, n. 3, pp. 289-298, 2015.

[31] FRANKEOVÁ, D., SLÍŽKOVÁ, Z. "Determination of the pozzolanic activity of mortar's components by thermal analysis," Journal of Thermal Analysis and Calorimetry, v. 125, n. 3, pp. 1115-1123, 2016.

[32] DONATELLO, S., TYRER, M., CHEESEMAN, C.R. "Comparison of test methods to assess pozzolanic activity," Cement and Concrete Composites, v. 32, n. 2, pp. 121-127, 2010.

[33] ASSOCIAÇÃO BRASILEIRA DE NORMAS TÉCNICAS - ABNT, "NBR 15895: Materiais pozolânicos - Determinação do teor de hidróxido de cálcio fixado - Método Chapelle modificado." 2010.

[34] QUARCIONI, V.A., CHOTOLI, F.F., COELHO, A.C.V., et al. "Indirect and direct Chapelle's methods for the determination of lime consumption in pozzolanic materials." Revista Ibracon de Estruturas $e$ Materiais, v. 8, n. 1, pp. 1-7, 2015.

[35] HOPPE FILHO, J., GOBBI, A., PEREIRA, E., et al. "Atividade pozolânica de adições minerais para cimento Portland (Parte I): índice de atividade pozolânica com cimento cal (IAP), difração de raios-x (DRX) e Chapelle modificado," Revista Matéria, v. 22, n. 3, 2017.

[36] HOPPE FILHO, J., GOBBI, A., PEREIRA, E., et al. "Atividade pozolânica de adições minerais para cimento Portland (Parte II): Índice de atividade pozolânica com cimento Portland (IAP), difração de raios-X (DRX) e termogravimetria (TG/DTG)," Revista Matéria, v. 22, n. 3, 2017.

[37] MEHTA, P.K., MONTEIRO, P.J.M. Concreto: estrutura, propriedades e materiais. São Paulo: Ibracon, 2014.

[38] DIAMOND, S., SAHU, S., THAULOW, N. "Reaction products of densified silica fume agglomerates in concrete," Cement and Concrete Research, v. 34, pp. 1625-1632, 2004.

[39] RAVERDY, M., BRIVOT, F., PAILLERE, M.A., et al. "Appreciation of pozzolanic reactivity of minor components," 1980.

[40] NEITHALATH, N., PERSUN, J., HOSSAIN, A. "Hydration in high-performance cementitious systems 
containing vitreous calcium aluminosilicate or silica fume," Cement and Concrete Research, v. 39, n. 6, pp. 473-481, 2009.

[41] BHATTY, J.I., REID, K.J. "Use of thermal analysis in the hydration studies of a type 1 portland cement produced from mineral tailings," Thermochimica Acta, v. 91, pp. 95-105, 1985.

[42] ZELIĆ, J., RUŠIĆ, D., VEŽA, D., et al. "Role of silica fume in the kinetics and mechanisms during the early stage of cement hydration," Cement and Concrete Research, v. 30, n. 10, pp. 1655-1662, 2000.

[43] BHATTACHARYA, M., HARISH, K.V. "An integrated approach for studying the hydration of portland cement systems containing silica fume," Construction and Building Materials, v. 188, pp. 1179-1192, 2018.

[44] PAPADAKIS, V.G. "Experimental investigation and theoretical modeling of silica fume activity in concrete," Cement and Concrete Research, v. 29, pp. 79-86, 1999.

[45] JEONG, Y., KANG, S.H., KIM, M.O., et al. "Acceleration of cement hydration from supplementary cementitious materials: Performance comparison between silica fume and hydrophobic silica," Cement and Concrete Composites, v. 112, n. May, pp. 1-10, 2020.

[46] SNELLINGS, R., SCRIVENER, K.L. "Rapid screening tests for supplementary cementitious materials: past and future," Materials and Structures, v. 49, n. 8, pp. 3265-3279, 2016.

[47] MITCHELL, D.R.G., HINCZAK, I., DAY, R.A. "Interaction of Silica Fume With Calcium Hydroxide Solutions," Cement and Concrete Research, v. 28, n. 11, pp. 1571-1584, 1998.

[48] WANG, W., LIU, X., GUO, L., et al. "Evaluation of properties and microstructure of cement paste blended with metakaolin subjected to high temperatures," Materials (Basel)., v. 16, n. 6, 2019.

[49] CORDEIRO, L.N.P., MASUERO, A.B., DAL MOLIN, D.C.C. "Analysis of potential pozzolanic ash from rice husk (cca) using the technique of rietveld refinement," Revista Matéria., v. 19, n. 2, pp. 150-158, 2014.

[50] MEDEIROS, M.H.F., RAISDORFER, J.W., HOPPE FILHO, J., et al. "Partial replacement and addition of fly ash in Portland cement: influences on carbonation and alkaline reserve," J. Build. Pathol. Rehabil., v. 2, n. 1, pp. 1-9, 2017.

[51] ABO-EL-ENEIN, S.A., EL-KADY, G., EL-SOKKARY, T.M., et al. "Physico-mechanical properties of composite cement pastes containing silica fume and fly ash," HBRC Journal, v. 11, n. 1, pp. 7-15, 2015.

[52] GÓMEZ-ZAMORANO, L.Y., GÁRCIA-GUILLÉN, G., ACEVEDO-DÁVILA, J.L. "Estudo da hidratação de pastas de cimento Portland com substituições de escória granulada de alto forno, cinza volante e metacaulim: efeito da utilização de dois aditivos superplastificantes," Revista ALCONPAT, v. 5, n. 3, pp. 203-218, 2015.

[53] ROSSEN, J.E., LOTHENBACH, B., SCRIVENER, K.L. "Composion of C-S-H in pastes with increasing levels of silica fume addition," Cement and Concrete Research, v. 75, pp. 14-22, 2015.

[54] CASCUDO, O., FERNANDES, J.H.A., SANTOS, T.O., et al. "Contribuição à caracterização nanoestrutural de pastas de cimento por meio da técnica de microscopia de força atômica," Revista Matéria., v. 23 , n. 1,2018

\section{ORCID}

Marcella Amaral

Gustavo Macioski

Marcelo Henrique Farias de Medeiros
https://orcid.org/0000-0002-7783-691X

https://orcid.org/0000-0001-8489-4328

https://orcid.org/0000-0003-3112-9715 